\title{
Air embolism during posterior spinal fusion
}

A 12-year-old healthy girl underwent a 13-level posterior spinal fusion with Harringron rod, Luque instramentation and Drum. mond spinous process wires for scoliosis repair. Her anosithetic induction and initial intraoperative course were complesely uneventful until a precipitous blood pressure drop occurred accompanied by a significant decrease in heart rate. The Harrington rod was being manipulated at the same time as bone chips were being removed from the iliac crest. Although more common intraoperative events were presumed and treatment initiated, venous air embolism (VAE) was considered the aetiology of these events when a iransien decrease in the end-tidal carbon dioxide $\left(E T C \mathrm{O}_{2}\right)$ and an increase in the end-idal nitrogen $\left(E T N_{2}\right)$ was noted by mass spectrometry. This transient episode resolved within a relatively narrow window of time, and the case proceeded without further incident including a wake-up test, to the conclusion of surgery.

The pathophysiology, diagnosis and treatment of VAE have been extensively discussed in the anaesthesia literature. Methods of detection include the use of a precordial doppler, ${ }^{1}$ oesophageal stethoscope ${ }^{2}$ measurements of ETCO $_{2},{ }^{1} \mathrm{ETN}_{2},{ }^{3}$ pulmonary artery pressure, ${ }^{4,10}$ transoesophageal echocardiography and transcutaneous $\mathrm{O}_{2}$ and $\mathrm{CO}_{2}$ monitoring. ${ }^{5,6}$ These methods vary in their reported sensitivity, specificity, and clinical usefulness.

Air emboli have been reported following many surgical procedures including hip surgery, ${ }^{7}$ epidural catheter insertion, ${ }^{8}$ radical hysterectomy, ${ }^{9}$ laparoscopy and hysteroscopy, ${ }^{10}$ and during surgery involving the head and neck. " To our knowledge, VAE has not been reported during posterior spinal fusion. The following report describes a case of haemodynamically significant VAE

\section{Key words:}

EMBOLISM: air; MONITORING: end-tidal nitrogen, end-tidal carbon dioxide; SURGERY: orthopaedic, scoliosis.

From the Department of Anesthesiology, The Children's Hospital, 300 Longwood Avenue, Boston, Massachusetts, 02115.

Address correspondence to: Dr. Hotzman, 300 Longwood Avenue, Boston, Ma. 02115. during Harrington Rod placement, accompanied by a change in $\mathrm{ETN}_{2}$ and $\mathrm{ETCO}_{2}$ concentrations, measured by mass spectrometry.

\section{Case report}

A 12-year-old, $50 \mathrm{~kg}$ white female underwent a $\mathrm{T}_{3}-\mathrm{L}_{1}$ posterior spinal fusion with Harrington rod, Luque instrumentation and Drummond spinous process wires for repair of a 40 degree thoracic curvature.

Her past medical history revealed a mild upper respiratory tract infection treated effectively with penicillin one week prior to admission. Preoperative laboratory studies, physical examination and chest $x$-ray were normal. The patient was classified as ASA physical status class I.

The patient received $7 \mathrm{mg}$ diazepan PO preoperatively. Anaesthesia was induced one hour later using thiopentone, $250 \mathrm{mg}$, fentanyl $650 \mu \mathrm{g}$, and pancuronium $6 \mathrm{mg}$. The trachea was intubated with a $7.0 \mathrm{~mm}$ culfed orotracheal tube and anaesthesia was maintained with 70 per cent $\mathrm{N}_{2} \mathrm{O}$ and $0.5-1.5$ per cent isoflurane through a seniclosed circle absorption system. Ventilation at a tidal volume of $900 \mathrm{ml}$ and rate of nine was controlled by a hanging bellows pneumatic anaesthesia ventilator (Drager). Monitoring was established with an ECG, precordial and oesophageal stethoscope, oral temperature probe, as well as a radial artery and central venous pressure (CVP) line passed through the antecubital fossa to the right atrium, confirmed by continuous waveform monitoring. A mass spectrometer (SARA System, Allegheny International Medical Technology) was attached to the elbow of the breathing circuit. A foley catheter was placed in the bladder for measurement of urinary output, and the patient positioned prone on a Relton-Hall frame.

Two hours into the procedure the blood pressure precipitiously dropped from a stable $110 / 60 \mathrm{mmHg}$ to $78 / 50 \mathrm{mmHg}$, associated with a brief decrease in heart rate from 96 to 64 , and a CVP decrease from 7 to $5 \mathrm{mmHg}$ (baseline in prone position was $6 \mathrm{mmHg}$.) The Harrington rod was being manipulated simultaneously with bone chips being removed from the right iliac crest. Lactated Ringer's solution $(500 \mathrm{ml})$ and ephedrine $5 \mathrm{mg}$ were given, with resolution of symptoms over two to three minutes. VAE was not initially considered because of its unlikely occurrence during a posterior spinal fusion; other more likely causes for a decrease in blood pressure were sought. 
Examination of the mass spectrometer readings after stabilization revealed changes suggestive of VAE, i.e., during the hypotensive episode the $\mathrm{ETCO}_{2}$ decreased from 4.9 to 4.0 per cent. Within one minute, the $\mathrm{ETN}_{2}$ rose from 0.2 to 18.4 per cent. At no time was the classical "mill-wheel murmur" heard. Recognizing the potential for VAE as an additional uetiology of the above events, the $\mathrm{N}_{2} \mathrm{O}$ was discontinued and an oxygen-air-isoflurane anaesthetic used. The surgeons were informed of this new working diagnosis, and immediately packed both operative fields with saline-soaked sponges, which were then carefully removed. A minimal amount of air was extracted through the CVP line.

Gas delivery system dysfunction accounting for the combined picture of a decrease in $\mathrm{ETCO}_{2}$ and an increase in $\mathrm{ETN}_{2}$ was quickly checked for and ruled out: there was no leak in the tracheal tube cuff, the patient did not evidence spontaneous breathing either by physical exam or notching of the capnographic waveform, there were no disconnects detected (no appreciable change in ventilation by physical examination, consistent peak airway pressures, and absence of low pressure alarm). The total fresh gas flow of $4.0 \mathrm{~L} \cdot \mathrm{min}^{-1}$ remained consistent throughout.

Changes in the efficiency of oxygenation were estimated by shunt calculation using the respiratory index $\left[\mathrm{Qs} / \mathrm{Qt}=6\left(\mathrm{PAO}_{2}-\mathrm{PaO}_{2} / \mathrm{PaO}_{2}\right)+7\right],{ }^{12}$ with a baseline calculation of 11.9 per cent, pre-embolism value of 11.8 per cent, and a value ten minutes after the acute episode of 12.8 per cent. No further treatment was required, and the case proceeded uneventfully, including a wake-up test, to the conclusion of surgery. The patient was extubated in the operating room and had an uneventful postoperative course.

\section{Discussion}

VAE has nol been previously reported with a posterior spinal fusion, and although part of the differential diagnosis during an episode of haemodynamic instability, it is not the most likely cause. In procedures where VAE is considered a significant risk, appropriate monitoring and anticipation of the potential problem make diagnosis easier and treatment rapid and effective. Monitoring techniques are mentioned earlier; treatment methods include lowering of the surgical field below the level of the heart, flooding of the field with fluid, and aspiration of a CVP line.

In our case, important changes in vital signs occurred concurrent with changes in end-tidal gas concentrations measured by the mass spectrometer. Blood loss in excess of appropriate volume replacement is the most common reason for intraoperative hypotension during this procedure. Other causes of sudden hypotension during scoliosis surgery include pneumothorax, transfusion reactions during blood administration, and extrinsic pressure placed on the infrior vena cava through the surgical site. Our measured blood loss of $240 \mathrm{ml}$ had been replaced until the time of the hypotension with $1000 \mathrm{ml}$ of lactated Ringer's solution, with a CVP reading of $5 \mathrm{mmHg}$. Bradycardia, rather than tachycardia, accompanied this decrease in blood pressure, possibly reflecting an increase in vagal tone secondary to surgical stimulation, or hypoxia secondary to mechanical dysfunction of the ventilator or gas delivery system. At no time did the fraction of inspired or exhaled nxygen change. Half of the surgical team was indeed manipulating the Harrington rod simultaneous with the bradycardia, and when questioned, reported that the amount of distraction being applied was minimal, and no direct pressure was being put on the spinal cord. The other half of the surgical team was working in the open iliac crest bone graft site.

Mechanical dysfunction was ruled out by careful examination of the patient, the mechanical ventilator, and the gas delivery system. There was no change in circuit peak airway pressure noted, nor any difference in breath sounds by auscultation. A tracheal tube leak, which could account for the decrease in $\mathrm{ETCO}_{2}$ and elevation in $\mathrm{ETN}_{2}$, even in the absence of a low pressure alarm, ${ }^{13}$ was not cvidenced by physical examination. The anaesthesia circuitry was found to be completely intact without evidence of disconnection or air leak. Furthermore, while a decrease in total fresh gas flow has been noted to present with the same expiratory gas monitoring picture ${ }^{13}$ by entrainment through circuit leaks, the total fresh gas flow was held constant throughout our case at 4.0 $\mathrm{L} \cdot \mathrm{min}^{-1}$. Spontaneous breathing in a partially paralyzed patient likewise may be associated with a similar expiratory gas pattern. Our patient was well relaxed, without any spontaneous respiratory efforts noted by physical exam or by notching in the capnographic waveform. Controlled mechanical ventilation with judicious pasitive pressure is generally favoured in scoliosis surgery, as negative expiratory pressure during mechanical ventilation can theoretically contribute to a decrease in venous pressure, and therefore encourage air embolism. ${ }^{14}$ We were fortunate in having both a mass spectrometer and an ECG with printer attachments and so could document the rapid changes in expired gases associated with the changes in blood pressure and pulse (Figure). Unfortunately, the shared nature of the mass spectrometer provided discontinuous samples (in our case every 36 seconds), rather than more recently available mass spectrometer capnographs or infrared capnometers, which operate on a continuous breath-by-breath basis.

After a working diagnosis was made of VAE, the inspired gas mixture was changed to isoflurane/ 


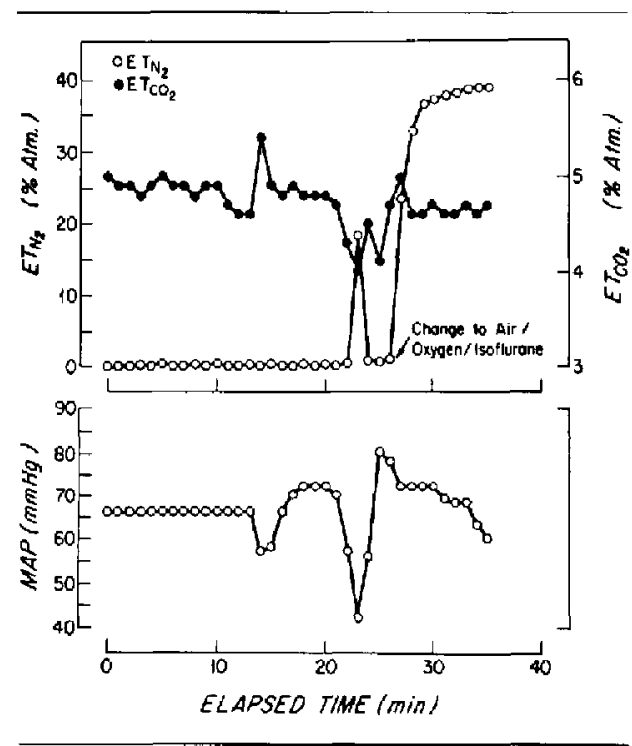

FIGURE Plot of end-tidal nilrogen and end-tidal carbon dioxide vs time showing changes in gas concentrations, and the decrease in mean blood pressure during the venous air embolism. The second increase in end-tidal nitrogen occurs as the inspired gas mixturc is changed from nitrous oxide/oxygen to airfoxygem.

air/oxygen, in order to avoid further exposure to nitrous oxide, and the potential for expansion of air emboli. Steffey el al. investigated the cardiovascular effects of VAE during air and oxygen breathing in dogs, and determined that while a 100 per cent oxygen environment reduced the severity of adverse cardiovascular effects of VAE during slow air entry into the circulation, there was no difference in recovery of mean arterial pressure following experimental air embolism whether in an air/oxygen or 100 per cent oxygen environment. ${ }^{15}$

In order to entrain air into the venous system, a vein must be open to the environment with a venous pressure less than ambient pressure. In our patient, many factors make VAE worthy of consideration in the differential diagnosis. An open venous plexus may have been present in either the iliac crest or the spinous processes of the vertebrae. In addition, the Relton-Hall frame on which this patient was placed is specifically designed to lessen blood loss during spinal surgery by decreasing intraabdominal pressure. This decreases the blood flow (and blood pressure) in the epidural venous plexus encouraging the return of blood from the lower extremities via the inferior vena cava. ${ }^{16}$ Several other manoeuvres are often used in this type of surgery to decrease blood loss. With controlled hypotensive anacsthesia, both mean arterial pressure and CVP are lowered, using either an arterial or venous dilator like nitroprusside or nitroglycerin, moderately high doses of inhalation agents to decreasc systemic vascular resistance and lower cardiac output, or by with holding fluids to maintain a low CVP. The combination of patient position and anaesthetic technique may therefore fayour VAE occurrence.

The sensitivity of ETN 2 detection compares favourably with other methods of VAE detection; it is also very specific, and may therefore enhance our monitoring for this potentially catastrophic event. At the same time, the rapid return to baseline of ETN $\mathrm{N}_{2}$ (earlier than $\mathrm{ETCO}_{2}$ ) may be falsely construed as resolution of the VAE, while residual air in the larger vessels of the pulmonary circuit has not yet achieved alveolar equilibration, ${ }^{17}$

The number of variables involved in attempting to relate the amount of air entrained to $\mathrm{ETN}_{2}$ concentration, including duration of entrainment, rate of release of air from veins to alveoli and movement of air from alveoli up the bronchial tree make a mathematical calculation very complex and probably inaccurate. Losee et al. ${ }^{18}$ injected known amounts of air into the venous circulation of a dog, and $\mathrm{ETN}_{2}$ measurements were obtained. The ETN $\mathrm{ENot}_{2}$ nod after injection of $5 \mathrm{ml} \cdot \mathrm{kg}^{-1}$ air was 2.5 per cent. Extrapolating to our case, an ETN 2 of 18.4 per cent would require close to $35 \mathrm{ml} \cdot \mathrm{kg}^{-1}$ of air to be entrained, an amount potentially lethal. We do not know the duration of entrainment in our uncontrolled situation, but only the time course of clinically significant haemodynamic effects and expiratory gas measurements. The rate of entrainment into the circulation and the rate of releasc into the alveoli may modify the clinical effects.

In conclusion, we have described the occurrence of a VAE during posterior spinal fusion, a complication not previously noted during this procedure. We made this diagnosis utilizing the $\mathrm{ETN}_{2}$ and $\mathrm{ETCO}_{2}$ levels measured by a mass spectrometer in conjunction with compatible clinical findings. Applying data from Losee et al. we used the $\mathrm{ETN}_{2}$ concentration to attempt to calculate the amount of air entrained, and arrived at surprisingly high amounts. Further research in correlating ETN $N_{2}$ and air entrainment is needed.

\section{References}

1 Chang JL, Abbin MS, Bunegin L, Hung TK. Analysis and comparison of venous air embolisml detection methods Neurosurgery 1980: 7; 135 .

2 Buckland $R W$. Venous air embolism during neurosurgery: a comparison of various methods of detection in man. Anaesthesia 1976: 3L; 633.

3 Matiasko $M J$. Sensitivity of end-tidal nitrogen in venous air embolism detection in dogs Anesthesiology: 1985: $63 ; 418$. 
4 Marshall $K$. Use of a pulmonary artery catheter for detection and treatment of venous air embolism; a prospective study. Anesthesiology 1980: 52; 131.

5 Glerski JA, Cucchiara RF. Michenfelder JD. Transesophageal echocardiography and transcutaneous $\mathrm{O}_{2}$ and $\mathrm{CO}_{2}$ manitoring for detection of venous air embclism. Anesthesiology 1986: 64: 541 .

6 Glenski JA, Cucchiara RF. Transcutaneous $\mathrm{O}_{2}$ and $\mathrm{CO}_{2}$ monitoring of neurosurgical patients: detection of air embolism. Anesthesiology 1986: 64; 546.

7 Michel $R$. Air embolism in hip surgery. Anaesthesia 1980 $35 ; 858$.

8 Nauity JS, Ostheimer GW, Datta S, Knapp R, Weiss $J B$. Incidence of venous air embolism during epidural catheter insertion. Anesthesiology 1982: 57; 410.

9 Naulty JS, Meisel LB, Datta S, Ostheimer GW. Air embolism during radical hystcrectomy. Ancsthcsiology 1932: $57 ; 420$.

10 Wadhwa RK, McKenzie R, Wadhwa SR, Katz $D L$, Byers $J F$. Gas embolism during laparoscopy. Anesthesiology 1978: $48 ; 74$.

11 Geevarghese KP. Anesthesia for neurological surgery. Int Anesthesiology Clin 1977: 15; 181.

12 Benumof JL, Rauscher A, Herren A. Comparison of respiratory index ( $\left[\mathrm{P}\left(\mathrm{AaDO}_{2} / \mathrm{PaO}\right)\right]$ with transpulmonary shunt. Abstracts of scientific papers, 1977 meeting, American Society of Anesthesiologists, 185.

13 Marjasko J, Gunselman J, Delaney J, Mackenzie. $C F$. Sources of nitrogen in the anesthesia circuit. Anesthesiology 1986: 65; 229.

14 Reiton JES. "Anesthesia in the original correction of scoliosis" in Riseborough EJ, Herndon JH (Eds.) Scoliosis and Other Deformities of the Axial Skeleton Boston, Little Brown, 1975.

15 Sieffey EP, Gauger GE, Eger EI. Cardiovascular effects of venous air embolism during air and oxygen breathing. Ancsth. Analg. 1974: 53; 599.

16 Reiton JES, Hall JE. An operation frame tor spinal fusion. J Bone Joint Surg 1967: 49B; 327.

17 Drummond JC, Prutow RI, scheller MS. A comparison of the sensitivity of pulmonary artery pressure, end-tidal carbon dioxide and end-tidal nitrogen in the detection of venous air embolism in the dog. Anesthesiology 1985 : 64; 688 .

18 Losee JM, Sherrill D, Virtue RW, Lechner AJ. Quantitative detection of venous air embolism in the dog by mass spectrometry measurement of end tidal nitrogen. Anesthesiology 1982: 57; A146.
Résumé

Une fille de 12 ans en bonne santé a subi une opération pour correction de scoliose. L' induction de l' anesthésie ainsi que le maintien furent sans conséquence jusqu'à ce qu' on observe une chute imporante de la tension artérielle accompagnée d"une diminution de la fréquence cardiaque. La tige de Harrington était à ce moment-là manipulée êt même temps qu'on enlevait des copeaux d'os de la crête iliaque. Même si on pensı̃ et amorça le traitement des causes les plas communes de cette hypotension, l'embolie veineuse aérienne (VAE) a été cansidérée comme la cause de cet évènement quand on observa une diminution transitoire de la $\mathrm{PCO}_{2}$ en fin d"expiration et une augmentation de la $P N_{2}$ en fin d'expiration avec un spectromère de masse. Cetre épisode transitoire s'est résolu en un temps relativement court et la chirurgie a procédé sans autre incident. 